\title{
Modelling of Traffic Flow on West Jakarta Highways
}

\author{
Ahmad Faza ${ }^{\# 1}$, Friska Natalia ${ }^{* 2}$ \\ Universitas Multimedia Nusantara, Tangerang, Indonesia \\ 1ªhmad.faza@student.umn.ac.id \\ ${ }^{2}$ friska.natalia@umn.ac.id
}

\begin{abstract}
Congestion is one of the problems faced by people who use land transportation modes and live in Jakarta. Congestion occurs because the number of vehicles is much more than road capacities and traffic infrastructure. As a result, the flow of those vehicles becomes jammed. Efforts that can be done to handle traffic problems include traffic engineering, road widening, and build new road. The traffic engineering process requires an information on traffic congestion conditions. Those information is used for distributing the traffic flows from the congested roads to some alternative roads. Data is collected by using Google Maps API. This data is analysed using visual data mining method. The result is presented on the dashboard to show congestion based on road segments, days, and hours. An application is developed to accommodate this feature. So it will help to know which roads are the most congested and afterwards, users can avoid those roads.
\end{abstract}

Keyword - Dashboard, Data Visualization, Google Maps, Pentaho, Traffic Jam

\section{INTRODUCTION}

Congestion is one of the problems faced by people who use land transportation modes and live in large urban areas. Congestion occurs because the number of vehicles is much more than road capacities and traffic infrastructure [1]. Congestion has huge negative impact, such as fuel wastage, time wastage, and environmental damage due to air pollution released by motor vehicles [2]. Efforts that can be done to handle traffic problems include traffic engineering, road widening, and build new road. The traffic engineering process requires an information on traffic congestion conditions. Those information is used for distributing the traffic flows from the congested roads to some alternative roads. Data is collected by using Google Maps API. This data is analyzed using visual data mining method. The result is presented on the dashboard to show congestion based on road segments, days, and hours.

Several previous studies or journals that use as reference or reference for doing this research. The first study visualize the traffic congestion at Beijing. Speed and road network used and collected by used GPS mounted on taxi [3]. The second study gave information about traffic flow condition and alternative route to avoid congestion. Data collected by used Google Maps API. Dijkstra algorithm used for get the shortest route to avoid congestion [4]. The third study was monitoring the traffic flow condition on real-time. Monitoring process use air platform to capture road condition and ground platform to process the video captured by the air platform [5]. The last study was develop the model of traffic congestion corridor which is used for decision support system. Modelling process was done by use two method: volume capacity ratio (VCR) and volume per lane (VPL). VCR calculated based on engineering design perspective classification. VPL calculated based on traffic speed limit [6]. The objective of this research is to select the coordinate point on the road that will be studied to get traffic density data based on the color grouping in Google Maps API to be visualized in the dashboard of traffic density.

\section{Problem Statement ANd Methodology}

This study use Rapid Application Development as a system development methods and Visual Data Mining as data visualization method. Visual Data Mining is used as data visualization method for it capability to clean, transform and visualize traffic condition data that have gathered into traffic condition dashboard. Figure 1 shows the step of Visual Data Mining method. 


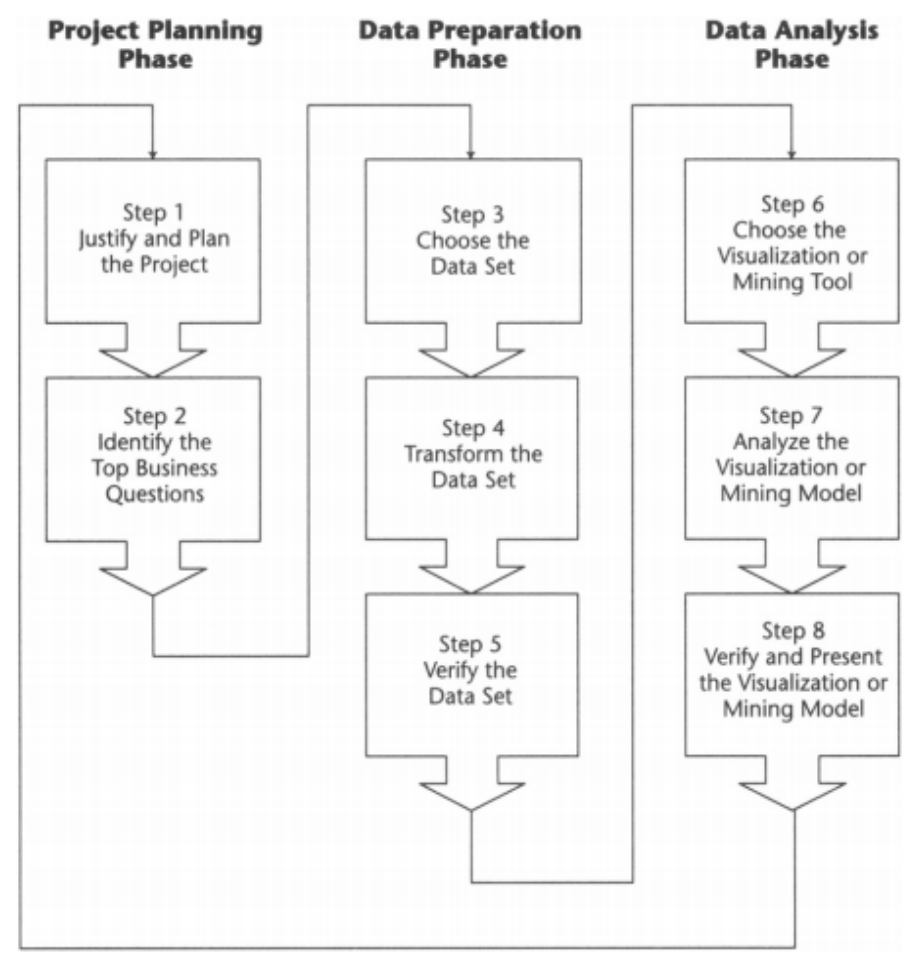

Fig. 1. Visual Data Mining

Following are phase for modelling traffic flow condition data using visual data mining method:

a) Project Planning Phase: Planning the process and goals for traffic condition data visualization. Identify the main users for traffic condition data visualization

b) Data Preparation Phase: Choose the data set, transform the data set and verify the data set that used as source for traffic condition dashboard

c) Data Analysis Phase: Choose the tools for visualization, analyse the visualization result and verify the result to the main users.

Rapid Application Development model is an application development model with short development cycles, application development based on components, and reuse of code or code generation. Figure 2 shows the step of Rapid Application Development model.

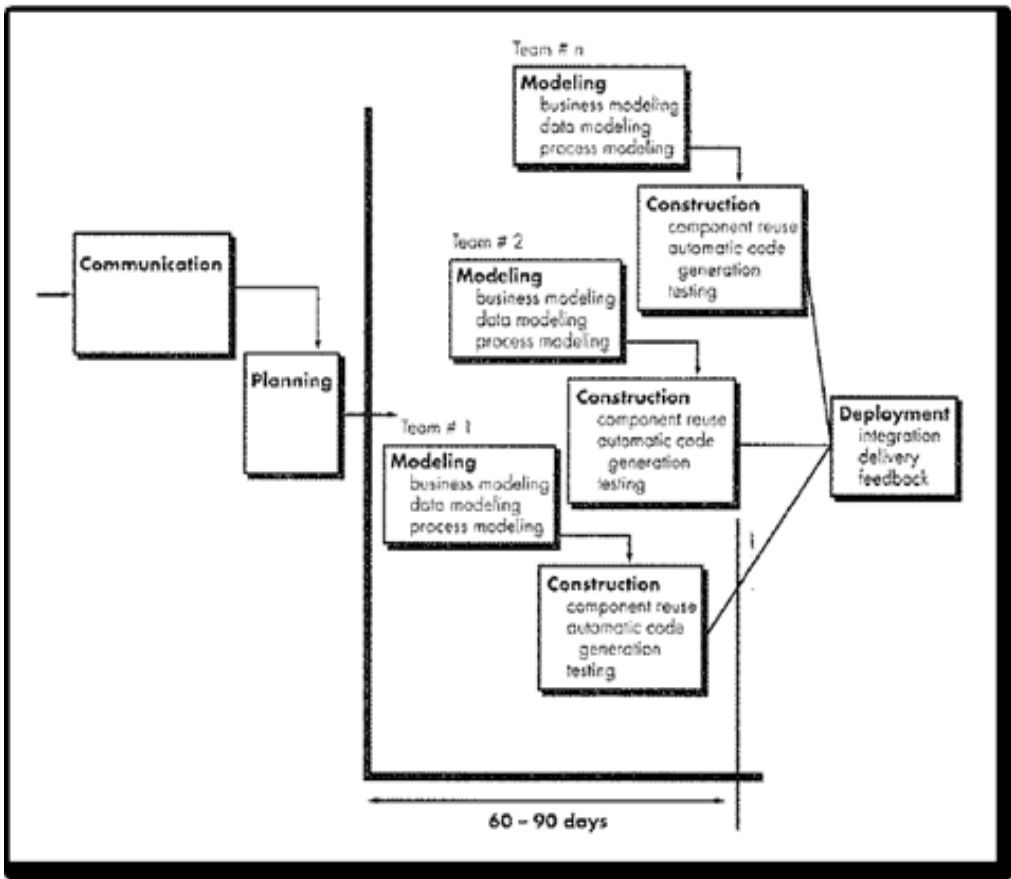

Fig. 2. Rapid Application Development 
Following are phase for developing traffic flow condition dashboard using rapid application development method:

a) Communication: Domain problem in this research is traffic condition of toll road section and characteristic of information that must be produced is traffic condition classification of toll road segment

b) Planning: Planning process for developing web that integrate with google maps API and determine data model for visualization process.

c) Modelling: Modelling the data to meet the visualization requirement

d) Construction: Constructing website for gathering the traffic condition data and dashboard for visualize the traffic condition data

e) Deployment: Deployment phase end by testing the User Acceptance Test to the user.

\section{EXPERIMENT AND RESULTS}

A. Communication

Problem domain in this research is control input to traffic condition of tolls road section. There are four toll roads used for collecting the traffic condition data. The toll roads are:

a) Jakarta - Tangerang.

b) Prof. Sedyatmo.

c) Jakarta Outter Ring Road

d) Jakarta Inner Ring Road

The four toll roads divided by the direction of traffic flow, which are clockwise and counter clockwise. Data collecting process is done for 30 days starting at $00.00 \mathrm{WIB}$ and end at $23.00 \mathrm{WIB}$. The information requirement for this data collecting process is classification of traffic condition on toll roads based on colors generated from Google Maps API. The result from classification then presented in pie chart. Table 1 are the colors generated from Google Maps API.

TABLE I. Colors and Traffic Condition Information

\begin{tabular}{|l|l|l|l|l|l|}
\hline \multirow{2}{*}{ No. } & \multicolumn{3}{|l|}{ Colors Code } & \multirow{2}{*}{ Colors } & $\begin{array}{l}\text { Traffic } \\
\text { Condition }\end{array}$ \\
\cline { 2 - 4 } & Red & Green & Blue & & Fast \\
\hline 1. & 153 & 204 & 102 & & Moderate \\
\hline 2. & 255 & 102 & 0 & & Slow \\
\hline 3. & 255 & 0 & 0 & & Queueing \\
\hline 4. & 153 & 0 & 0 & & \\
\hline
\end{tabular}

B. Planning

\section{1) Determining Coordinate Points.}

Coordinate points used as starting point for color detection process. The coordinate point obtained by using matrix distance feature in Google Maps API. The distance between coordinate point is $250 \mathrm{~m}$. The distance is determine during observation using google maps for one weeks. Table 2 are the result from determining coordinate points:

TABLE II. Total Point Coordinate for Each Toll Roads

\begin{tabular}{|l|l|l|l|}
\hline No. & Toll Roads & Total Points & Direction \\
\hline 1. & Jakarta - Tangerang & 28 & Clockwise \\
\hline 2. & Jakarta - Tangerang & 28 & Counter Clockwise \\
\hline 3. & Jakarta Outter Ring Road & 33 & Clockwise \\
\hline 4. & Jakarta Outter Ring Road & 33 & Counter Clockwise \\
\hline 5. & Prof. Sedyatmo & 22 & Clockwise \\
\hline 6. & Prof. Sedyatmo & 22 & Counter Clockwise \\
\hline 7. & Jakarta Inner Ring Road & 19 & Clockwise \\
\hline 8. & Jakarta Inner Ring Road & 19 & Counter Clockwise \\
\hline
\end{tabular}

\section{2) Displaying the Maps.}

This process is requred for obtaining the image of four tolls roads. The images are used for color detection process. Figure 3 show the flow of this process. Due to display limitation of the web page, the map divided into 18 section. 


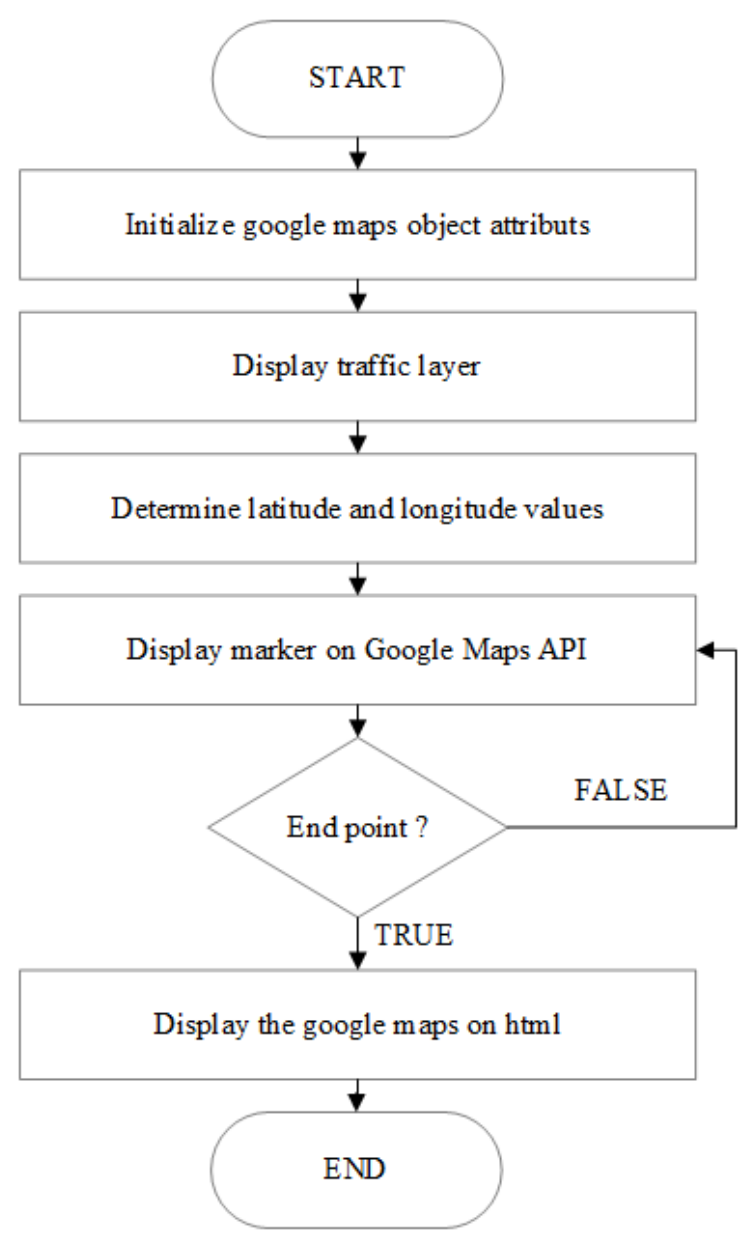

Fig. 3. Flowchart of display the map process

3) Saving the Image

The display from previous step then saved as image. Wkhtmltoimage application used for convert and save the display into image form. This image form is used for color detection process. Figure 4 show the flow of this process:

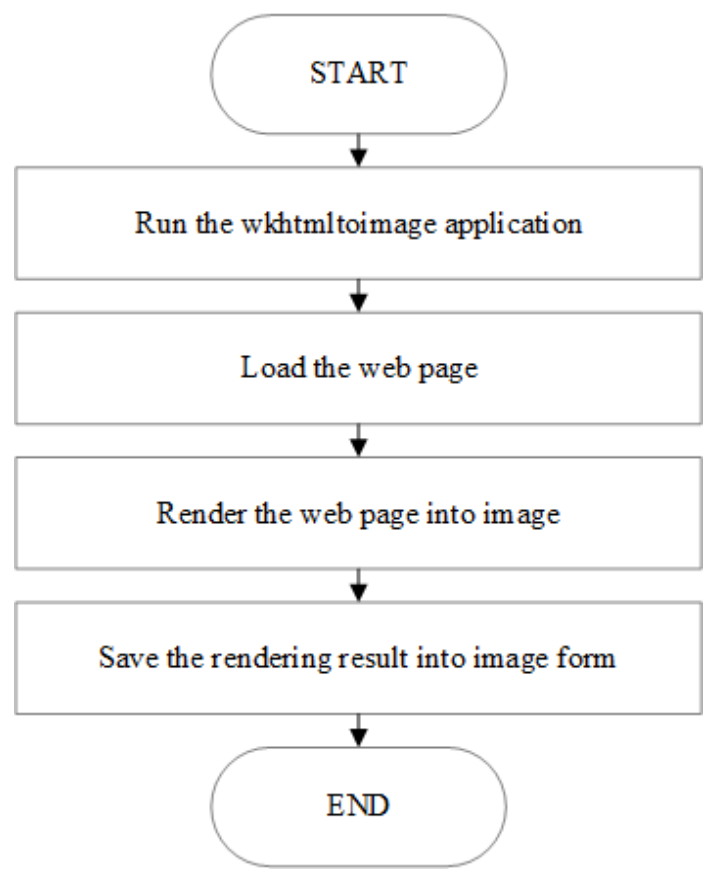

Fig. 4. Flowchart of save the image process 


\section{4) Converting Coordinate Value}

The coordinate values then converted into cartesians coordinate system. The cartesians coordinate value use for detect and capture image pixel's colors. Converting process use koordinat.php script. The converting process begin by execute koordinat.php script on localhost. Then select the coordinate value by pointing the cursor on marker. Then click on the marker to get cartesian coordinate value.

\section{5) Colors Detection}

The colors detection process are done by using script_color.inc.php and deteksi.php. The script_color.inc.php is used for recurring color detection process. The deteksi.php is used for determining the image source, giving $\mathrm{x}$ and $\mathrm{v}$ value, displaying the result from detection color process, and storing the result into database.

\section{Modelling}

The modelling phase is prcess to extract, transform and load the source data to meet the requirement for data visualization.

\section{1) Color Cleansing}

The color cleansing process is done to find and fix the colors that do not match with the color from Table 1. This colors missmatch caused by shifting coordinate values when load the web page. The cleansing process rule is the y point value are move untill the colors match the criteria with the maximum value of 10 point. Table 3 shows the example of the missmatch colors.

TABLE III. Colors Missmatch Example

\begin{tabular}{|l|l|l|l|l|}
\hline \multirow{2}{*}{ No. } & \multicolumn{3}{|c|}{ Colors Code } & \multirow{2}{*}{ Colors } \\
\cline { 2 - 4 } & Red & Green & Blue & \\
\hline 1. & 204 & 204 & 204 & \\
\hline 2. & 255 & 204 & 102 & \\
\hline 3. & 255 & 51 & 0 & \\
\hline 4. & 255 & 51 & 51 & \\
\hline 5. & 0 & 0 & 0 & \\
\hline 6. & 204 & 153 & 51 & \\
\hline
\end{tabular}

2) Time Cleansing

The time cleansing process fix the latency of timestamp by two minutes tolerance. This late occur caused by the delay of loading the page and detecting colors process. The cleansing process is done by roinding the mintes to 0 so the hours become exact. Table 4 shows the example of timestamp latency.

TABLE IV. Timestamp Latency Example

\section{3) Creating Table}

\begin{tabular}{|c|c|c|}
\hline No & Before & After \\
\hline 1. & $00: 03$ & $00: 00$ \\
\hline 2. & $01: 03$ & $01: 00$ \\
\hline 3. & $02: 03$ & $02: 00$ \\
\hline 4. & $03: 03$ & $03: 00$ \\
\hline
\end{tabular}

The database used for data visualization consists of 3 data tables. The tables are:

- ms_time: to store hours and minutes data.

- $\quad$ ms_road: to store roads name and regions name data

- fact_traffic: to store the calculation of each traffic condition data.

Table 5 shows the ms_time table structure, Table 6 shows the ms_road table structure and Table 7 shows the fact_traffic table structure. 
TABLE V. ms_time Table Structure

\begin{tabular}{|l|l|l|l|}
\hline No & Name & Type & Primary \\
\hline 1. & roads_sk & Integer(11) & Yes \\
\hline 2. & roads_id & Varchar(30) & - \\
\hline 3. & roads & Varchar(30) & - \\
\hline 4. & regions_id & Varchar(30) & - \\
\hline 5. & regions & Varchar(30) & - \\
\hline
\end{tabular}

TABLE VI. ms_road Table Structure

\begin{tabular}{|l|l|l|l|}
\hline No & Name & Type & Primary \\
\hline 1. & time_id & $\operatorname{Varchar}(20)$ & Yes \\
\hline 2. & days & $\operatorname{Varchar}(20)$ & - \\
\hline 3. & hours & Varchar(20) & - \\
\hline
\end{tabular}

TABLE VII. fact_traffic Table Structure

\begin{tabular}{|l|l|l|l|}
\hline No & Name & Type & Primary \\
\hline 1. & roads_sk & Integer(11) & Yes \\
\hline 2. & roads_id & Varchar(20) & - \\
\hline 3. & time_id & Varchar(20) & - \\
\hline 4. & fast & Integer(30) & - \\
\hline 5. & moderate & Integer(30) & - \\
\hline 6. & slow & Integer(30) & - \\
\hline 7. & queueing & Integer(30) & - \\
\hline
\end{tabular}

\section{4) Creating Schema}

The traffic schema created based on ms_road, ms_time, and fact_traffic tables. Figure 5 shows the traffic scheme structure. This schema use star schema for each dimension tables and fact tables. The dimension use on schema are Region Dimension and Time Dimension. Region Dimension uses ms_road as data source and Time dimension use ms_time as source data. The fact_traffic consists four measurements, which are:

- Fast: for calculate occurance of fast traffic condition

- Moderate: for calculate occurance of moderate traffic condition.

- Slow: for calculate slow traffic condition

- Queueing: for calculate quequeing traffic condition.

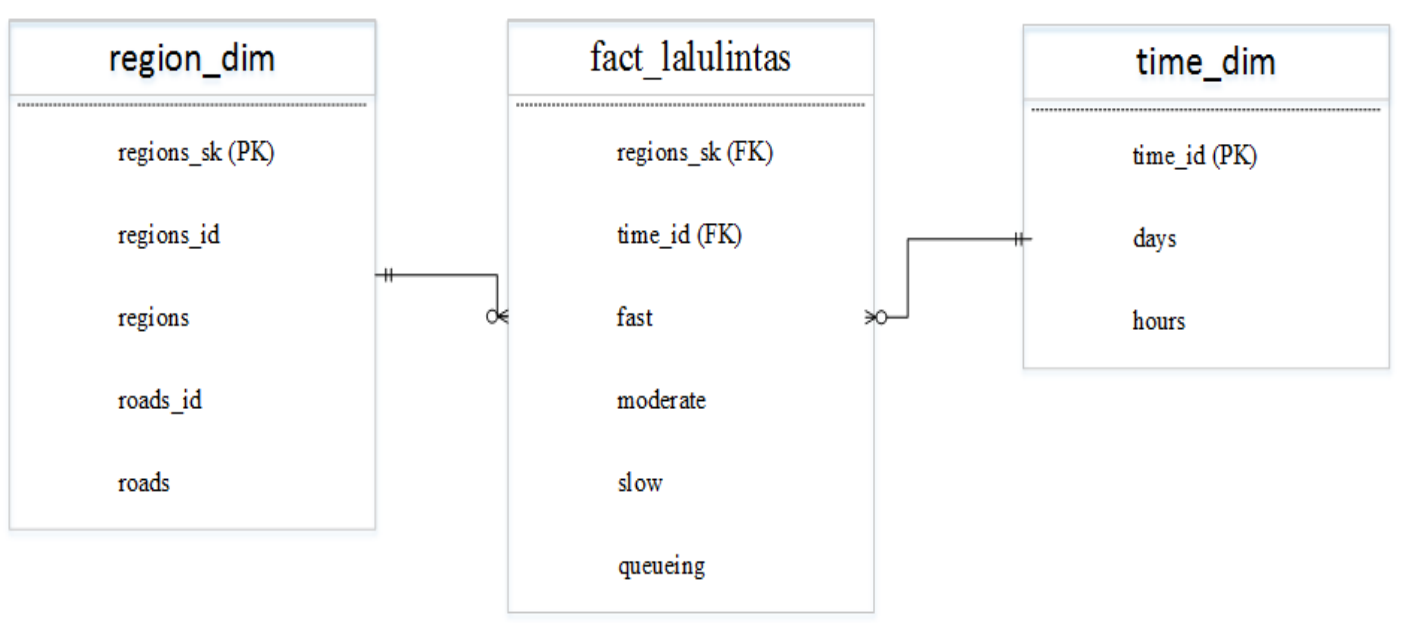

Fig. 5. Traffic Schema Structure

\section{Contruction}

The construction of dashboard traffic condition use Pentaho Community Dashboard Edition. The dashboard consists of three interface. The first interface shows the overview of traffic condition on each toll roads. The second interface shows the information of traffic condition on one toll road based on days. The third interface 
shows the information of traffic condition on one toll road based on hours. Figure 6 shows the main dashboard interface.

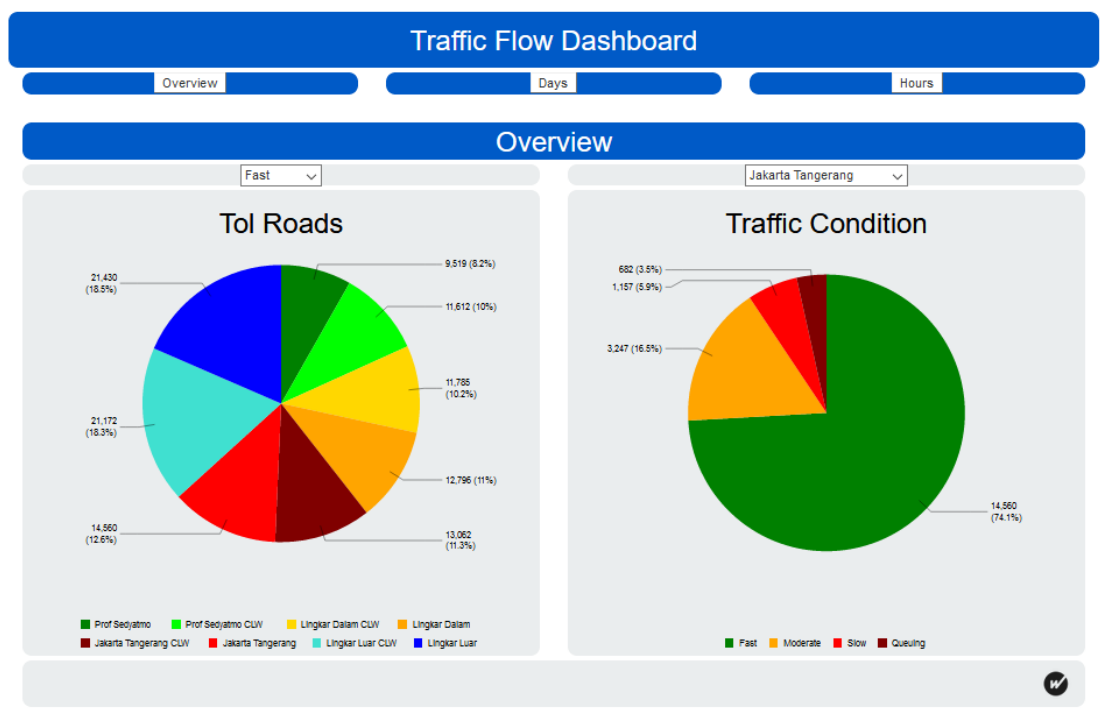

Fig. 6. Main Dashboard Interface

The header from the main dashboard use to navigate through the daily traffic condition dashboard and hourly traffic condition dashboard. There are two parameters to filter the information that showed on pie charts. The parameters are traffic condition parameter toll road parameter. The traffic condition parameter used to filter the traffic condition information based on traffic condition. The toll road parameter used to filter the traffic condition information based on toll roads name. There are two pie charts to visualize the traffic condition data. The first pie chart show all the toll roads traffic condition based on selection of traffic condition. The second pie chart shows the traffic condition information based on selection of toll roads. Figure 7 describes the daily traffic dashboard interface.

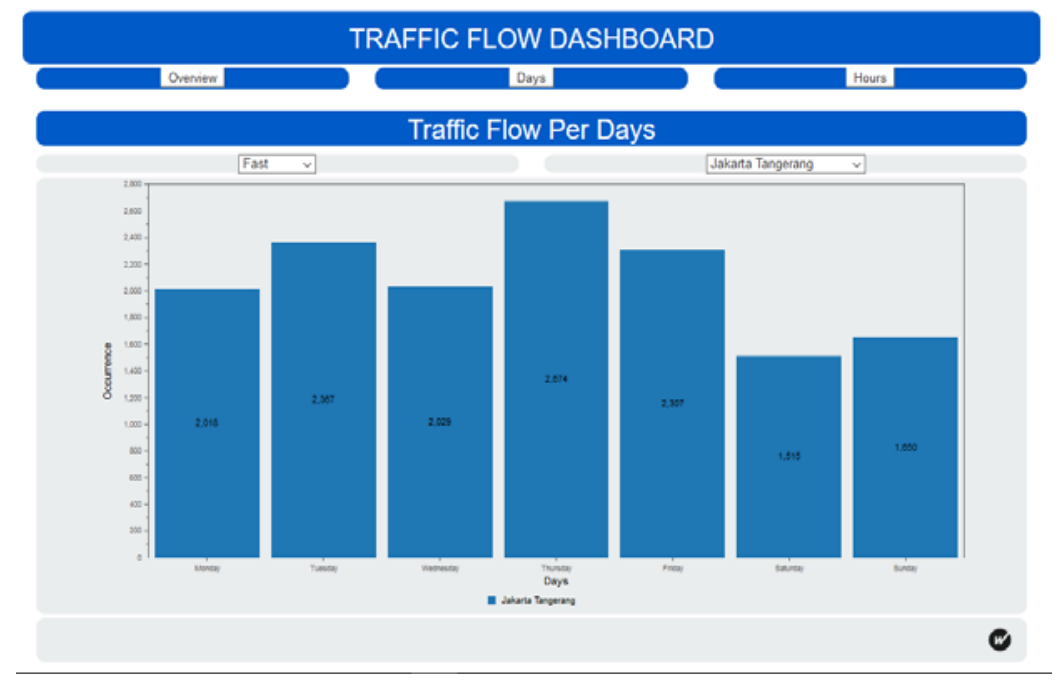

Fig. 7. Daily Traffic Dashboard Interface

There are two parameters to filter the information that showed on bar chart. The parameters are traffic condition and parameter toll road parameter. The traffic condition parameter used to filter the traffic condition information based on traffic condition. The toll road parameter used to filter the traffic condition information based on toll roads name. Bar chart use to visualize the daily traffic condition data. The $\mathrm{x}$ axis shows the name of the days and the y axis shows the occurances of traffic condition in one day. Figure 8 shows the hourly traffic dashboard interface. 


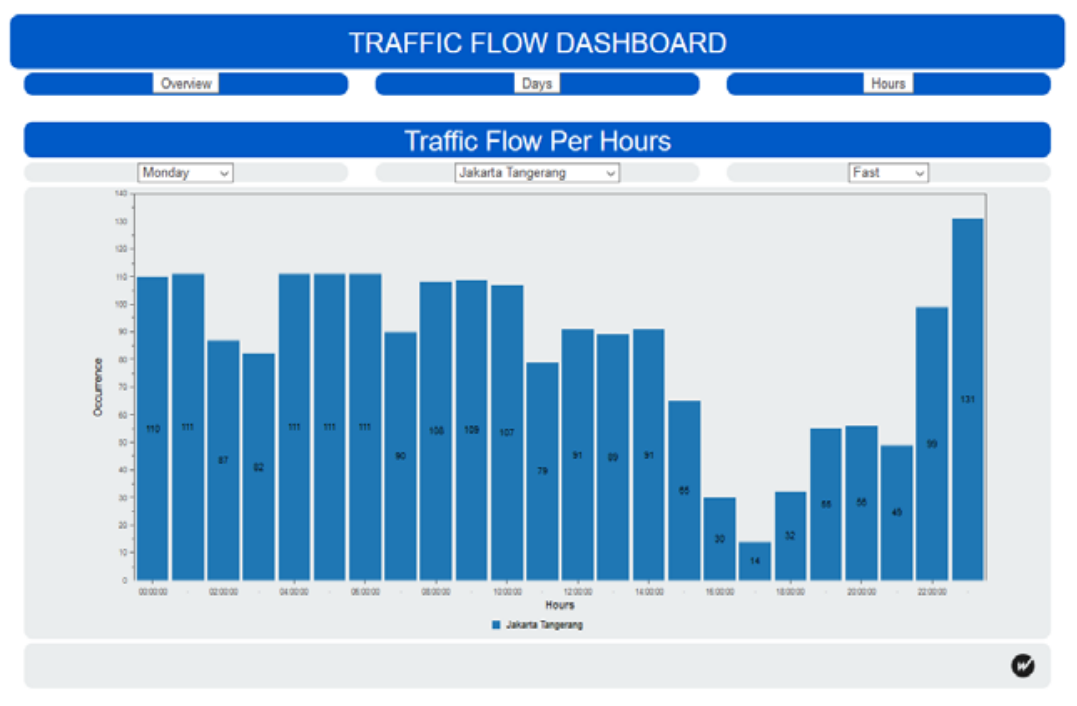

Fig. 8. Hourly Traffic Dashboard Interface

There are three parameters to filter the information that showed on bar chart. The parameters are traffic condition parameter, toll road parameter, and day parameter. The traffic condition parameter used to filter the traffic condition information based on traffic condition. The toll road parameter used to filter the traffic condition information based on toll roads name. The day parameter used to filter the traffic condition information based on days. Bar chart use to visualize the daily traffic condition data. The $\mathrm{x}$ axis shows the hours and the $y$ axis shows the occurances of traffic condition in hours.

The traffic condition dashboard is presented to PT. Jasa Marga (Persero) as a toll roads operation manager for verifying process. The verifying process uses user acceptance test (UAT) to measure the user capability to use and understand the information result from the dashboard. The test shows that each visualization can be understand by the user and the information generated from dashboard meet the information requirement. Each dashboard interface score $70 \%$ and function test score $85 \%$. User suggests to add traffic condition information based on kilometer mark which placed on the toll roads.

E. Analysis Results

Table 8 shows the results of designing traffic flow model on West Jakarta Highways as follows:

TABLE VIII. Analysis Results

\begin{tabular}{|l|l|l|}
\hline \multicolumn{1}{|c|}{ Categories } & \multicolumn{1}{c|}{ Before } & \multicolumn{1}{c|}{ After } \\
\hline $\begin{array}{l}\text { Traffic congestion ration } \\
\text { between toll roads }\end{array}$ & $\begin{array}{l}\text { Total traffic congestion occurs } \\
\text { between toll roads cannot be } \\
\text { compared }\end{array}$ & $\begin{array}{l}\text { Total traffic congestion occurs between } \\
\text { toll roads can be compared and } \\
\text { visualized on pie chart }\end{array}$ \\
\hline $\begin{array}{l}\text { Highest traffic congestion } \\
\text { occurs on day }\end{array}$ & $\begin{array}{l}\text { Highest traffic congestion } \\
\text { occurs on day cannot be } \\
\text { determined }\end{array}$ & $\begin{array}{l}\text { Highest traffic congestion occurs on } \\
\text { daily can be determined and visualize } \\
\text { on bar charts }\end{array}$ \\
\hline $\begin{array}{l}\text { Highest traffic congestion } \\
\text { occurs on hour }\end{array}$ & $\begin{array}{l}\text { Highest traffic congestion } \\
\text { occurs on hour cannot be } \\
\text { determined }\end{array}$ & $\begin{array}{l}\text { Highest traffic congestion occurs on } \\
\text { hour can be determined and visualize } \\
\text { on bar charts }\end{array}$ \\
\hline
\end{tabular}

\section{IV.CONCLUSION}

In this research, it can be concluded that this dashboard succeeded to give traffic condition information on West Jakarta highways based on color classification generated by Google Maps API. Then coordinat point selection by using matrix distance feature provided in Google Maps. This feature uses to determine the distance between point that been use in selection process. The coordinat point value then obtained by using "what's here' feature in Google Map. Those value use as a reference for color detection process. Then the traffic condition data gathered by classifying the color generated by Google Map. Those colors generated by rgb code. There are 5 colors use as reference for traffic condition information, as follow: $(150,204,102)$ as fast, $(255,102,0)$ as moderate, $(255,0,0)$ as slow, and $(153,0,0$ or $204,0,0)$ as queueing.

Then color detection process is done by using color.inc.php script. Latitude and longitude value then converted into cartesian coordinat value. This script then use cartesian coordinat value as reference for detecting colors. Then development of dashboard use rapid application development method. This method consists of 5 step to be done. The first step is communication, which determine the goals for developing this dashboard. The 
goal is to provide information about traffic condition on West Jakarta highways that presented on graph. The second step is planning, which is prepare and planning to gather the data. The third step is modelling, which is the data processed to meet the requirement for visualization process. The fourth step is construction, which is the process of creating interface and function on dashboard begin. The fifth step is verification, which the dashboard is tested by user using user acceptance test to measure the ability for user to use and understand the information provided from dashboard. The all interface score $70 \%$ and the functionality score $85 \%$.

Suggestion given to continue this research as follows:

a. Store the dashboard application into virtual private network to make the dashboard available for public use.

b. The roads for traffic condition monitoring can be broaden to included all Jakarta regions.

c. The reference for color detection can use kilometer sign located on the side of tolls road.

\section{ACKNOWLEDGMENT}

The heading of the Acknowledgment section and the References section must not be numbered.

Causal Productions wishes to acknowledge Michael Shell and other contributors for developing and maintaining the IEEE LaTeX style files which have been used in the preparation of this template. To see the list of contributors, please refer to the top of file IEEETran.cls in the IEEE LaTeX distribution.

\section{References}

[1] Sudrajat, S. T., Road Toll Road Traffic Model In Partial Differential Equations: Universitas Padjadjaran, 2007.

[2] Bergkamp, D., Traffic Congestion DKI Jakarta, 2011.

[3] Wang, Z., Visual Traffic Jam Analysisbased on Trajectory Data. Beijing: VISPKU, 2013.

[4] Sari, P. W., Designing Alternative Route Searching System In Bandung To Avoid Traffic Jam By Utilizing Google Aplication Programming Interface (Fire) Based Android. Bandung: Telkom Press, 2014

[5] Luo, X. d., Vehicle flow detection in real-time airborne traffic surveillance system. Jurnal.Transactions of the Institute of Measurement and Control, 880 - 897, 2011.

[6] Seong, J., Modeling and Mapping Traffic-Congested Corridors For Statewide Decision Support. Advances in Cartography and GIScience, 2011.

[7] Peichao, Gao., Characterizing Traffic Conditions from the Perspective of Spatial-Temporal Heterogeneity. ISPRS Int. J. Geo-Inf. 2016, Vol 5, pp.34, 2011.

[8] Ponniah, Paulraj., Data Warehousing Fundamentals : A Comprehensive Guide for IT Profesionals. USA: John Wiley \& Sons,Inc., 2001.

[9] Weiskopf, D., GPU-Based Interactive Visualization techniques. Canada: Springer, 2006

[10] Schalkoff, Robert J., Digital image processing and computer vision. USA: John Wiley \& Sons, 1989

[11] Connolly, T., Begg C., Database System: A Practical Approach to Design, Implementation and Management. (4th Edition). New York: Addison Wesley, 2005

\section{AUTHOR PROFILE}

Ahmad Faza is a Student at Universitas Multimedia Nusantara. Young technopreneur with high passion in programing and business development. Have experienced with programing language like php and java.

Friska Natalia is Head of Research Centre in Multimedia Nusantara University also Lecturer in Department of Information Systems. She received her Ph.D. in Industrial Engineering from Kyungsung University, Busan, Republic of Korea. Her teaching and research interests include system and analysis design, logistics, e- business and computer programming. She can be reached by e-mail at friska.natalia@umn.ac.id 